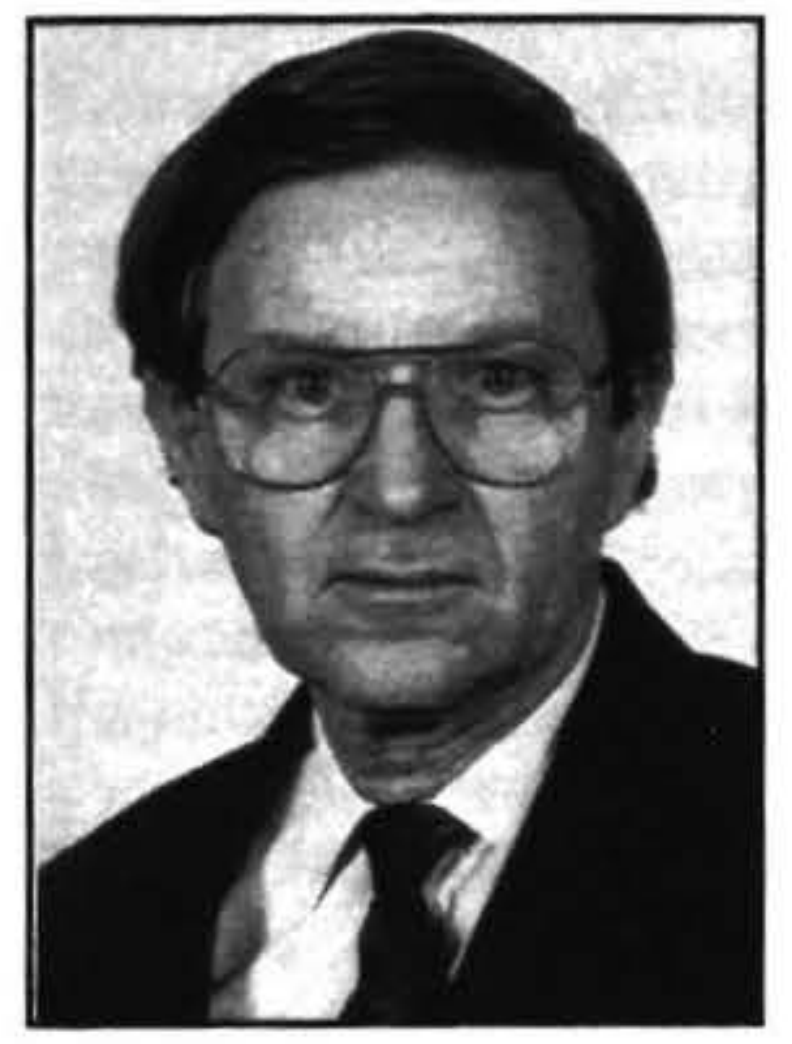

\title{
CHANGES IN REGIONAL INCOMES 1986 TO 1991
}

\author{
L. Fraser Jackson
}

Victoria University of Wellington

\begin{abstract}
This paper shows the importance of occupational detail in analysis of regional income distributions in New Zealand. Changes in regional incomes are shown to be linked to two main effects, those associated with changes in the occupational and workforce structure of the population, and to changes in national patterns in occupational incomes. Once these structural features have been included, there is little scope for remaining economic effects associated with labour force participation, and other features of the labour force. These observations are consistent with a rationing model as a primary means of describing the operation of local labour markets.
\end{abstract}

Many economic policies are premised on some view of the way in which the labour market operates. Models which emphasise flexibly operating markets generally assume prices provide the main signalling mechanism. However there has been widespread criticism of this model with respect to labour markets, and disequilibrium models with rationing in labour markets were developed to provide an alternative which is more consistent with a wide range of empirical evidence about persistence of unemployment. In these models other mechanisms perform the main signalling role. The rationing model expounded in Malinvaud(1977) is an excellent example of this range of ideas.

This model is referred to as a 'rationing' model because it regards wage rates as sticky prices which do not adjust downward to rates which would equate labour supply and labour demand. The positions available are rationed between those offering. The rationing process will normally depend on many factors and for some of these factors the individual labour market participant cannot modify them.

The rationing model has the implication that there may be major changes in labour force participation with little or no change in wage rates, and the disequilibrium created appears as unemployment or as withdrawal from the labour force. In the rationing model numbers of employees in different categories, such as full-time and part-time, for each sex group change in approximately parallel ways, with little or no change in wage rates.

In Jackson(1995) we examined the changes in employment in the regional units defined by the 1987 Parliamentary Electorates. For these units it was observed that there were correlated changes in the numbers of employees in the four categories defined, but there were also some changes in the patterns of employment, with a shift towards an increased share of part-time positions, and a shift in the balance of full time employees in favour of females. It was argued that these patterns were consistent with substitution in the demand for labour between classes of employees, and with a rationing model determining the persons actually in employment. Thus the classical substitution mechanism was observed in the structure of the persons in employment, but the rationing model appeared to be appropriate for analysis of the changes in the numbers in employment.

This conclusion can be thought of as implying that labour demand is governed by the usual economic substitution mechanisms with respect to types of labour employed. Many firms are operating at an output where they have the capacity to expand at the current prices, but are demand constrained. They purchase current inputs, including labour depending on the level of demand. Households find they face a varying labour demand over time, and are rationed with respect to the numbers employed. The ability of employers to vary wages in the short term is clearly limited, in part by equity considerations between short term and permanent employees, by differentials between occupations which may not be sustainable long term, and also by the tradeoffs between short term and potential long term employment opportunities for individuals. These factors and others constrain variability in the offered wage, and in many cases leave an excess supply of labour at the current wage.

A critical test of the rationing model requires income data. Such a test was not possible using data available at the time Jackson(1995) was written, since that paper demonstrated that there were very large occupation structure effects in mean income levels of the area units being used. Further the 1986 and 1991 Censuses used different occupational classifications, and the magnitude of the shifts between occupations at the major group level associated with the new 
classification was not clear. To enable exploration of the association of occupations and income levels, further data was obtained from Statistics New Zealand. This paper reports analysis of the observed income changes between 1986 and 1991 and an initial exploration of the income differences associated with numbers in the major occupational groups.

The title of this paper aims to provide a focus broader than just incomes of persons employed. We will examine incomes of those in employment for consistency with the alternative labour market models, but will also look at the ways in which the mean income in our areas is associated with a simple set of determining variables.

\section{The data set}

The analysis in this paper is largely based on two special tabulations from the Census. For 1986 a table of income, by labour force status by sex was available for each electorate, and used in Jackson(1995). Statistics New Zealand also published data by electorate on a number of variables using the 1987 electorates, and that source is used to give an occupational distribution by electorate of those in full time employment in the 1986 census. A national table of incomes by occupation for full time and part time employees was also available in 1986 Census reports. The second major tabulation provided a distribution of incomes for each occupation, sex and labour force status group for the 1991 Census using the 1987 electorates as the area units. The occupation classification used was the first digit level of the classification used in the 1986 Census, so the data could be analysed using the same broad occupation structure for both Census years.

\section{Occupational groups 1986 to 1991}

Using the above sources we can compile Table 1 which gives

Table 1. Occupation major group by fulltime and part-time by gender, New Zealand, 1991-1996

\begin{tabular}{lrrrr}
\hline & \multicolumn{2}{c}{ Full Time } & Part Time \\
& Male & Female & Male & Female \\
\hline Professional & 114,918 & 91,425 & 7,782 & 36,132 \\
Managerial & 62,052 & 15,033 & 1,725 & 3,132 \\
Clerical & 51,690 & 138,135 & 3,627 & 47,361 \\
Sales & 74,760 & 46,815 & 9,996 & 25,782 \\
Service & 47,316 & 45,912 & 8,331 & 43,779 \\
Agriculture & 88,380 & 24,693 & 8,226 & 12,957 \\
Production & 271,941 & 40,629 & 17,394 & 9,963 \\
NAD & 9,567 & 5,724 & 1,860 & 4,260
\end{tabular}

Changes 1991 Less 1986 Numbers

\begin{tabular}{lrrrr} 
& \multicolumn{2}{c}{ Full Time } & \multicolumn{2}{c}{ Part Time } \\
& Male & Female & Male & Female \\
Professional & 5,112 & 12,246 & 2,520 & 7,322 \\
Managerial & 2,730 & 4,881 & 579 & 582 \\
Clerical & $-12,471$ & $-11,325$ & 1,092 & 4,267 \\
Sales & 1,470 &, 735 & 3,726 & 2,441 \\
Service & $-1,434$ & $-3,294$ & 2,856 & 1,218 \\
Agriculture & $-15,594$ & $-3,351$ & 855 & -756 \\
Production & $-86,181$ & $-20,703$ & $-1,119$ & $-2,829$ \\
NAD & 2,082 & 2,817 & 1,083 & 3,366
\end{tabular}

Percentage change on 1986 Numbers

$\begin{array}{lrrrr} & \begin{array}{c}\text { Full Time } \\ \text { Male }\end{array} & \text { Female } & \begin{array}{c}\text { Part Time } \\ \text { Male }\end{array} & \text { Female } \\ \text { Professional } & 4.7 & 15.5 & 47.9 & 25.4 \\ \text { Managerial } & 4.6 & 48.1 & 50.5 & 22.8 \\ \text { Clerical } & -19.4 & -7.6 & 43.1 & 9.9 \\ \text { Sales } & 2.0 & 1.6 & 59.4 & 10.5 \\ \text { Service } & -2.9 & -6.7 & 52.2 & 2.9 \\ \text { Agriculture } & -15.0 & -11.9 & 11.6 & -5.5 \\ \text { Production } & -24.1 & -33.8 & -6.0 & -22.1 \\ \text { NAD } & 27.8 & 96.9 & 139.4 & 376.5\end{array}$

Source: Statistics New Zealand Census of Population and Dwellings, 1986,1991, special tabulations 
a consistent picture of the changes between the two censuses. These changes are generally small, but there was a notable reduction in the numbers in the production group in all categories of employment, even over-riding the general tendency for part-time employment to rise. There was also a large relative fall in the number of males engaged full time in clerical and agricultural occupations. The most significant increases were for females in professional and managerial occupations.

Incomes for the same categories are given in Table 2. For all occupational groups female incomes rose more rapidly than male incomes, but the levels for females in the same major occupational groups still lagged a long way behind males. Given that the census question asks for the annual income, this may be partly associated with other structural differences, such as different patterns of participation in full time employment but it is difficult to believe that this accounts for more than a modest part of the observed differences.

These two tables enable us to construct Figures $1 \mathrm{a}$ and $1 \mathrm{~b}$ which illustrate the changes in the employment income space. The convention in analysis of such a diagram is to assume that the supply is more stable than the demand, and that the points therefore provide information about the supply curve for labour. If we make that assumption, we can test if there is any evidence for some association between the changes in employment in the occupation groups and their relative incomes. Using weighted regression, with weights based on occupational group numbers in 1991, there was no evidence that changes in income and changes in employment were related. The occupation group markets may differ substantially in the slopes of the supply and demand func- tions. Nevertheless the small changes in relative income levels and the considerable changes in numbers employed in some groups is evidence that the supply functions over this period must have been very elastic. This is not inconsistent with using the rationing model considered earlier as a close approximation to the actual behaviour. If the conventional assumption of stability of supply is incorrect then interpretation of these changes is more difficult for an appropriate analysis then requires detailed knowledge of the structure of labour demand, and that is virtually impossible to obtain at the level of regional detail required.

\section{Modelling electorate income differences}

There are several ways in which the labour market impacts on the income distribution in the distinguished areas. First, the occupational distribution impacts on the income distribution of those in fulltime or part-time work. Second it impacts on the division of persons between the work force categories of fulltime, part-time, unemployed and non labour force.

In Jackson(1995) it was shown that for males employed full time there is a strong association between mean incomes predicted from a simple occupation based model, and actual incomes in each electorate. Let $\mathrm{w}_{\mathrm{ikt}}$ be the share of persons in group $\mathrm{k}$ in area $\mathrm{i}$ at time $\mathrm{t}$. In our application, the population referred to in an area may be all persons, or some sub-population in the area units, such as sex groups, or persons of a single sex in a work force category such as part time employment. Electorates are the only area units used.

Table 2. Mean income by occupation, fulltime/part-time and gender, 1991:1986

\begin{tabular}{llccc}
\hline & \multicolumn{2}{c}{ Full Time } & \multicolumn{2}{c}{ Part Time } \\
\hline & Male & Female & Male & Female \\
Professional & 46.8 & 30.5 & 28.3 & 15.0 \\
Managerial & 53.5 & 35.6 & 41.9 & 23.8 \\
Clerical & 33.2 & 23.1 & 16.9 & 12.9 \\
Sales & 33.5 & 20.4 & 9.4 & 9.1 \\
Service & 28.7 & 17.4 & 11.5 & 8.9 \\
Agriculture & 23.6 & 18.1 & 16.9 & 14.9 \\
Production & 25.9 & 16.4 & 16.5 & 9.9 \\
NAD & 24.7 & 17.1 & 16.2 & 13.7
\end{tabular}

Ratio Mean Income 1991 to Mean Income 1986

\begin{tabular}{lcccr} 
& \multicolumn{2}{c}{ Full Time } & \multicolumn{2}{c}{ Part Time } \\
Male & Female & Male & Female \\
Professional & 1.553 & 1.622 & 1.393 & 1.599 \\
Managerial & 1.553 & 1.651 & 1.372 & 1.625 \\
Clerical & 1.581 & 1.612 & 1.185 & 1.648 \\
Sales & 1.515 & 1.623 & 1.205 & 1.513 \\
Service & 1.445 & 1.527 & 1.374 & 1.609 \\
Agriculture & 1.534 & 1.686 & 1.352 & 1.889 \\
Production & 1.462 & 1.501 & 1.198 & 1.497 \\
NAD & 1.498 & 1.620 & 1.424 & 2.199 \\
\hline
\end{tabular}

Source: Calculated from special tabulations prepared by Statistics New Zealand. 
Figure 1a. Distribution of changes 1986-1991 in numbers and incomes for occupational groups in New Zealand. Males employed fulltime.

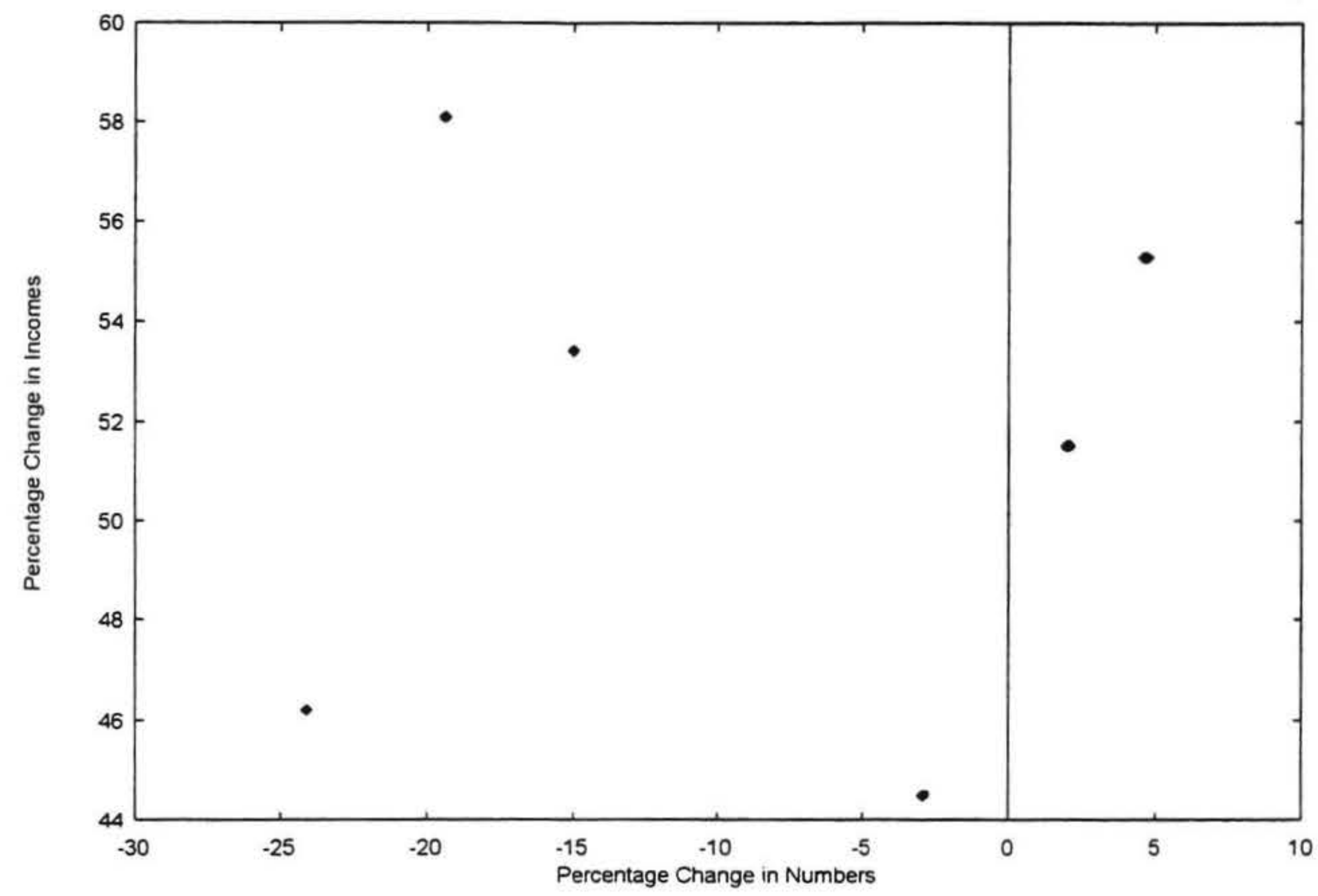

Figure 1b. Distribution of changes 1986-1991 in numbers and incomes for occupational groups in New Zealand. Females employed fulltime.

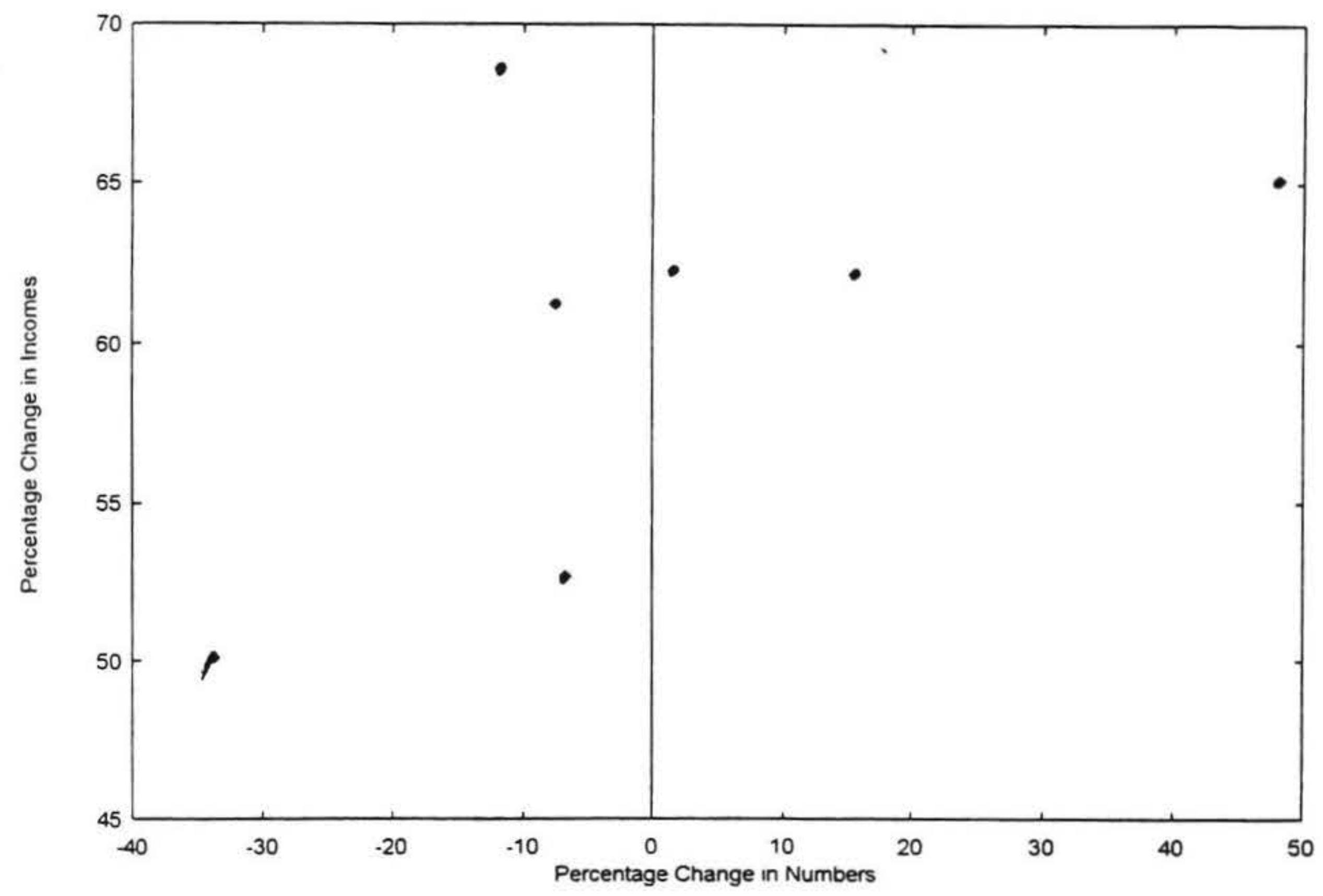


Note that $\Sigma \mathrm{k} \mathrm{w}_{\mathrm{ikt}}=1$. Let $\mathrm{y}_{\mathrm{k}_{\mathrm{k}}}$ be the mean income for each of the categories $\mathrm{k}$, and denote the mean income of all persons in group $\mathrm{k}$ at time $\mathrm{r}$ by $\mathrm{y}_{\mathrm{kr}}$. Now define

$$
\mathrm{z}_{\mathrm{it}}(\mathrm{r})=\Sigma \mathrm{k} \mathrm{w}_{\mathrm{ika}} \mathrm{y} \cdot \mathrm{kr} \text {. }
$$

Where $z_{\text {in }}(r)$ is the mean income across the groups of individuals $\mathrm{k}$ in electorate $\mathrm{i}$ using the mean incomes of persons in the whole population and in the equivalent groups at time $r$.

A simple model of income differences in the electorates can now be constructed. For all persons gainfully employed, persons can be distinguished by occupation, sex and whether full time or part time. For our data this gives eight occupation categories, and two levels for the fulltime, part-time split, or within each sex a total of 16 identified subgroups. Persons unemployed or not in the labour force can also be distinguished, and their mean incomes at the national level identified. Using these subgroups and (1) above we form the model

$$
y_{i t}=f\left(z_{i t}(t)\right)+e_{i t}
$$

with an error term $e_{\mathrm{it}}$. The results of plotting the dependent variable yit against the independent variable $\mathrm{z}_{\mathrm{it}}(\mathrm{t})$ are illustrated for 1991 in Figure 2. Males and females are treated as separate sub-populations within the population. The diagonal line shows where the dependent and independent variables equate. Within both groups the gradient of the relationship between the predicted and actual values is significantly greater than one. Clearly there are other factors also associated with occupation and employment participation which impact on income levels. Regression calculations reported in Table 3 show that for males in excess of 92 percent of the variance is accounted for by this relation, and for females 84 percent.

The lines through the two scatters are fitted regressions. The relationship appears to be linear for females, and approximately quadratic for males, and the pattern in the data shows that differences in the occupation structure are associated with a large part of the variance of mean incomes of the electorates.

\section{Income changes and workforce categories}

To obtain some understanding of income changes over time there are two aspects of the impact of the labour market on the area population which are important. Are changes in the occupation structure important in determining changes in the income levels of the population. The estimates presented in Figure 2 are based on all persons, and therefore include occupation groups for those in fulltime or part-time employment, and work force status (unemployed and seeking work, or non labour force) for those who are not employed. The distribution between working and non working individuals would be expected to be important in modifying the income levels. It is simple to assess the effects of this since the mean income for males is linear in the proportions of persons in

Figure 2. The contemporaneous relationship of the model and actual incomes. The regional distribution of males and female incomes in New Zealand, 1991.

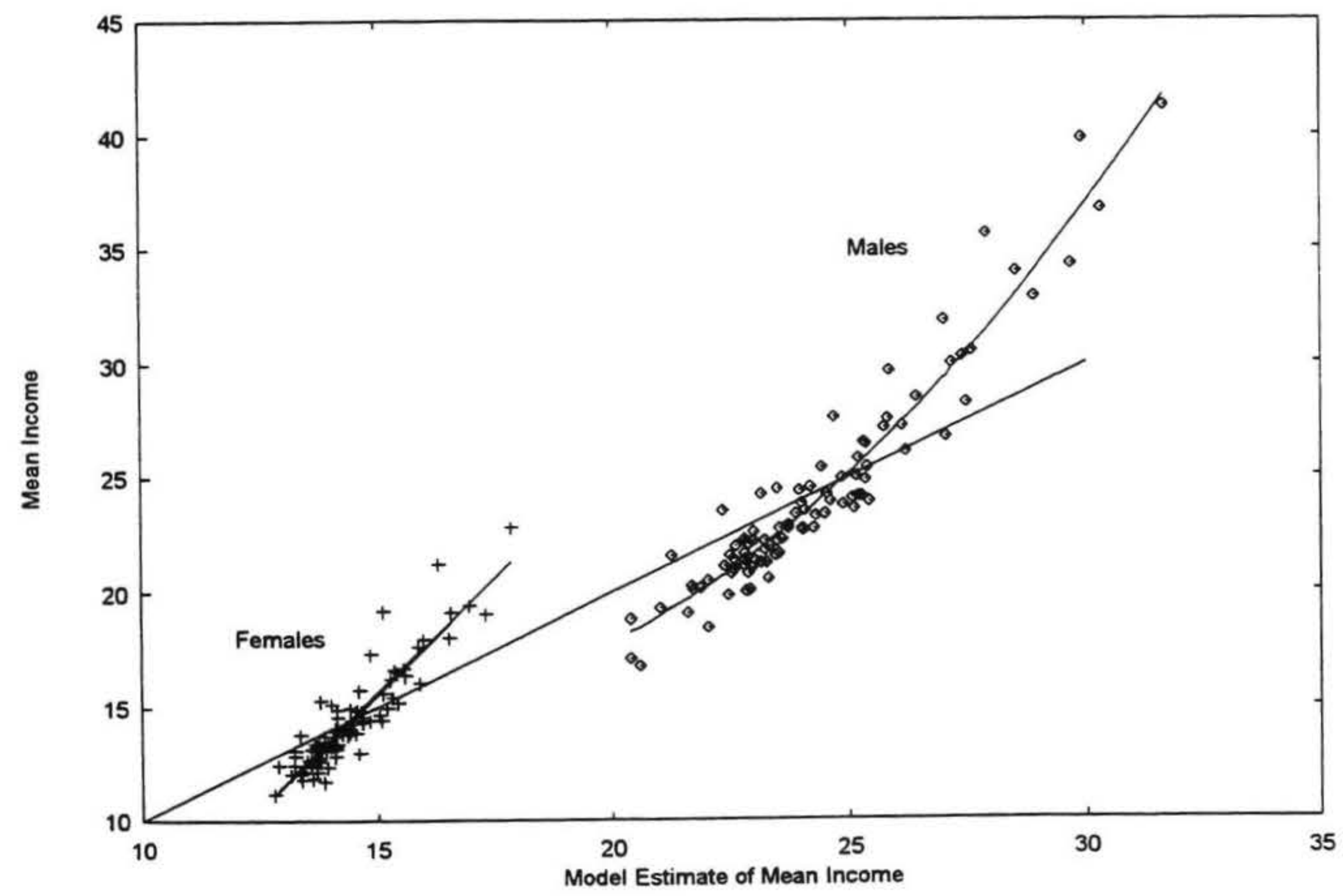




\begin{tabular}{|c|c|c|c|c|c|c|c|}
\hline Term & (2.1) & $(2.2)$ & ${ }_{(2.3)}{ }^{M}$ & $\begin{array}{l}\text { Model } \\
\qquad(2.4)\end{array}$ & (2.5) & (2.6) & (2.7) \\
\hline \multicolumn{8}{|l|}{ Males } \\
\hline Const & $\begin{array}{l}0.636 \\
(2.54)\end{array}$ & $\begin{array}{l}0.187 \\
(2.42)\end{array}$ & $\begin{array}{c}0.604 \\
(2.21)\end{array}$ & $\begin{array}{r}0.480 \\
(40.57)\end{array}$ & & & $\begin{array}{r}0.024 \\
(2.34)\end{array}$ \\
\hline $\ln y_{i t-1}$ & $\begin{array}{r}1.114 \\
(41.70)\end{array}$ & $\begin{array}{r}1.098 \\
(42.92)\end{array}$ & -1 & -1 & -1 & -1 & \\
\hline $\ln \mathrm{z}_{\mathrm{i}} \mathrm{t}-1(\mathrm{t}-1)$ & $\begin{array}{r}-1.719 \\
(-11.56)\end{array}$ & & $\begin{array}{r}-1.754 \\
(-10.82)\end{array}$ & & $\begin{array}{r}-1.512 \\
(-12.44)\end{array}$ & & \\
\hline $\begin{array}{l}\ln z_{i t}(t-1)- \\
\ln z_{i t-1}(t-1)-\end{array}$ & $\begin{array}{r}1.545 \\
(12.88)\end{array}$ & & $\begin{array}{r}1.711 \\
(13.82)\end{array}$ & & $\begin{array}{r}1.678 \\
(13.37)\end{array}$ & & \\
\hline $\mathrm{R}^{2}$ & 0.968 & 0.967 & 0.680 & 0.679 & 0.989 & 0.801 & 0.908 \\
\hline Std Error & 0.0312 & 0.0316 & 0.0340 & 0.0339 & 0.0348 & 0.1473 & 0.052 \\
\hline \multicolumn{8}{|l|}{ Females } \\
\hline Const & $\begin{array}{l}-0.228 \\
(-2.25)\end{array}$ & $\begin{array}{r}0.393 \\
(10.09)\end{array}$ & $\begin{array}{l}-0.120 \\
(-1.31)\end{array}$ & $\begin{array}{c}0.507 \\
(102.0)\end{array}$ & & & $\begin{array}{r}0.337 \\
(5.60)\end{array}$ \\
\hline $\ln y_{i t-1}$ & $\begin{array}{r}0.952 \\
(44.71)\end{array}$ & $\begin{array}{r}1.052 \\
(59.89)\end{array}$ & -1 & -1 & -1 & -1 & \\
\hline $\ln _{\text {zi } t-1}(t-1)$ & $\begin{array}{r}-1.095 \\
(-11.08)\end{array}$ & & $\begin{array}{r}-1.142 \\
(-11.58)\end{array}$ & & $\begin{array}{r}-1.177 \\
(-12.34)\end{array}$ & & \\
\hline $\ln _{\mathrm{zit}}(\mathrm{t}-1)$ & $\begin{array}{r}1.479 \\
(15.05)\end{array}$ & & $\begin{array}{l}1.429 \\
(14.6)\end{array}$ & & $\begin{array}{r}1.409 \\
(14.52)\end{array}$ & & \\
\hline $\begin{array}{l}\ln _{z i}(t-1)- \\
\ln _{z i} t-1(t-1)-\end{array}$ & & $\begin{array}{r}1.292 \\
(11.43)\end{array}$ & & $\begin{array}{r}1.298 \\
(11.01)\end{array}$ & & $\begin{array}{r}9.361 \\
(16.12)\end{array}$ & \\
\hline $\mathrm{R}^{2}$ & 0.983 & 0.977 & 0.719 & 0.571 & 0.998 & 0.738 & 0.942 \\
\hline Std Error & 0.0177 & 0.0212 & 0.0180 & 0.0221 & 0.0181 & 0.236 & 0.033 \\
\hline
\end{tabular}

Note: Terms in brackets are t-statistics

each category. However the analysis of change is made more complicated by the large differences in numbers in occupational categories for points depicted in Figure 2.

The simplest model of changes is that they are either the same linear or proportional amount for all persons. This is a good first approximation but it is improved by including quadratic components, which provide differential changes with income level shown in Figure 3.

Figure 3 shows clearly that a simple model of change appears to fit reasonably well. The dilemma that it gives the economist is that the importance of occupation structure outlined in Figure 2 means that small changes in the occupa- tional structure may be important in drawing any inferences from the data.

Since the Figures 2 and 3 are at the level of all incomes, we continue to examine the total income distribution, as affected by the interaction of households with the market. To examine this further we use mean incomes for the four workforce status groups (Full-time, Part-time, Unemployed, Non Labour Force) in construction of the indicator $z(t)$. The terms in the following models therefore permit a general pattern of change of the kind indicated in Figure 3, but applied to the logarithm of mean income, and adjustments based on the difference of the workforce status distribution in the two years. 


\section{Figure 3. Log 1991 mean income as a quadratic function of $\log 1986$ mean incomes. The regional distribution of males and female incomes in New Zealand.}

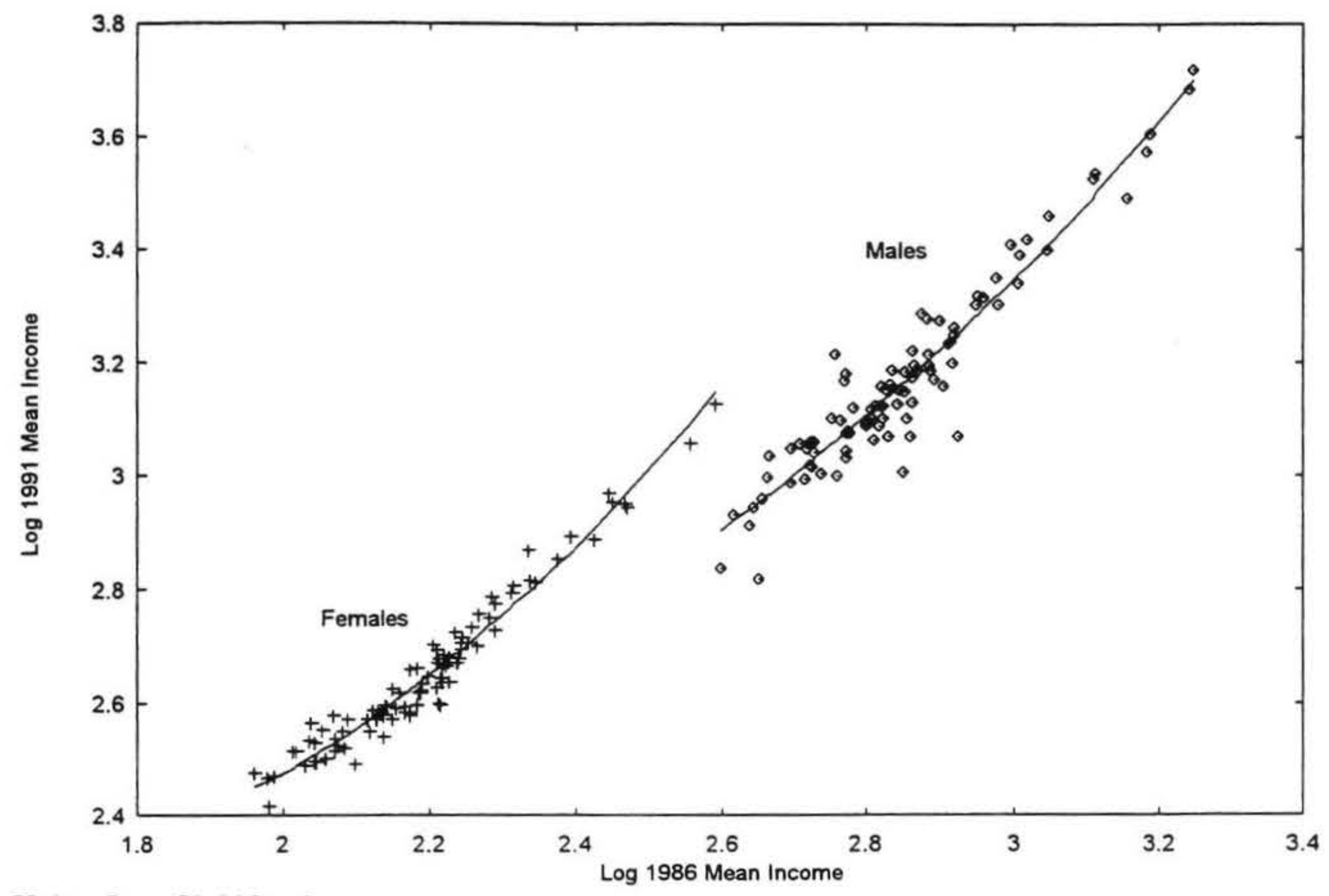

Units: $\log _{e} \$ 1,000=0$.

Consider the following models

$$
\begin{aligned}
& \ln \mathrm{y}_{\mathrm{it}}=\mathrm{a}+\mathrm{b} 1 \ln \mathrm{y}_{\mathrm{it} \cdot \mathrm{l}}+\mathrm{b}_{2} \ln \mathrm{z}_{\mathrm{Lt} \cdot \mathrm{t}}(\mathrm{t}-1)+\mathrm{b} 3 \ln \mathrm{z}_{\mathrm{it}}(\mathrm{t}-1) \\
& \ln \mathrm{y}_{\mathrm{it}}=\mathrm{a}+\mathrm{b} 1 \ln \mathrm{y}_{\mathrm{i}, \mathrm{l}-1}+\mathrm{b}_{2}\left(\ln \mathrm{z}_{\mathrm{i}, \mathrm{l}}(\mathrm{t}-1)-\ln \mathrm{z}_{\mathrm{it}}(\mathrm{t}-1)\right) \\
& \ln y_{i t}=a+\ln y_{i, t-1}+b_{2} \ln z_{t, t-1}(t-1)+b 3 \ln z_{i t}(t-1) \\
& \ln y_{i t}=a+\ln y_{i, t-1}+b_{2}\left(\ln z_{t s-1}(t-1)-\ln z_{i n}(t-1)\right) \\
& \ln y_{\mathrm{it}}=\ln \mathrm{y}_{\mathrm{i},-1}+\mathrm{b}_{2} \ln \mathrm{z}_{\mathrm{it}-\mathrm{l}}(\mathrm{t}-1)+\mathrm{b} 3 \ln \mathrm{z}_{\mathrm{it}}(\mathrm{t}-1) \\
& \ln y_{i t}=\ln y_{i t s-1}+b_{2}\left(\ln z_{i t, t-1}(t-1)-\ln z_{i t}(t-1)\right) \\
& \ln y_{i t}=a+b_{1} \ln y_{i,-1}
\end{aligned}
$$

Model (2.1) is the most general model in this set. When these models are fitted, it is found that a Wald test rejects the restrictions in nearly all cases, with the sole exceptions, model (2.2) for males, and model (2.5) for females. Given this result it seems appropriate to use the model (2.1) as the general model fitting this data. Estimates from these models are given in Table 3 . Note the substantial reduction in the standard error of the residuals between model (2.7) and model (2.1) for both males and females. This is clear evidence that the proportions in the workforce status groups were important in influencing the mean income levels at the electorate level. The fact that $\mathrm{b} 2$ and $\mathrm{b} 3$ have opposite signs and are similar in magnitude, implies that a first approximation is to think of the changes as dependent on the initial level of income, and a shift in the workforce status structure. Note that the coefficient on this difference is greater than 1 , which is consistent with the coefficients greater than one illustrated in Figures 2 and 3.

These models are not purely occupation structure models, since all increases are not directly proportional, but are associated with existing levels. However they have very little economic content, in that they are essentially only adjusting for changes in the occupation and workforce structure. It is remarkable that so much of the variance in income change can be explained solely in those terms, and suggests that structural impacts of economic policies in which the use of a resource changes will often generate the income impact of some economic policy measure. They seem to be largely changes determined by production technology.

To examine whether adding supply aspects of the labour market adds further explanatory power, consider the model

$\ln \mathrm{y}_{\mathrm{it}}=\mathrm{a}+\mathrm{b}_{1} \ln \mathrm{y}_{\mathrm{i}, \mathrm{t}-1}+\mathrm{b}_{2} \ln \mathrm{z}_{\mathrm{i}, \mathrm{t}-1}(\mathrm{t}-1)+\mathrm{b} 3 \ln \mathrm{z}_{\mathrm{it}}(\mathrm{t}-1)+\mathrm{b}_{4} \mathrm{n}+$ $\mathrm{b}_{\mathrm{s}} \mathrm{u}+\mathrm{e}_{\mathrm{it}}$

where $\mathrm{n}$ is the proportion of the group not in the labour force, and $\mathrm{u}$ is the proportion who report that they are unemployed and seeking work. The motivation for this model is that there are effects on incomes of all who are employed in a region if there is a high level of unemployment or a high level of non-participation in the labour force perhaps from discouraged worker effects. Table 4 gives the fitted values for the model (2.8). For males the Wald statistic is 8.04 with 2 and 87 degrees of freedom, so a modest improvement in fit is obtained, even though the coefficients individually are not significant. For females the Wald statistic for the additional terms is less than 1 and no improvement in fit is obtained. For males the estimated coefficients are negative, which 
Table 4. Fitted Values for Model (2.8)

\begin{tabular}{lcc}
\hline Term & Males & Females \\
\hline Const & 3.808 & -0.020 \\
& $(1.33)$ & $(0.04)$ \\
ln $y_{i t-1}$ & 1.089 & 0.958 \\
& $(41.55)$ & $(39.76)$ \\
ln $\mathrm{z}_{\mathrm{i} t-1}(\mathrm{t}-1)$ & -2.223 & -1.174 \\
& $(-10.60)$ & $(-7.75)$ \\
ln $\mathrm{z}_{\mathrm{i} t}(\mathrm{t}-1)$ & 1.043 & 1.470 \\
& $(1.048)$ & $(5.58)$ \\
nrate & -1.012 & -0.075 \\
& $(-1.29)$ & $(-0.49)$ \\
urate & -0.063 & 0.101 \\
& $(-0.07)$ & $(0.46)$ \\
R2 & 0.9734 & 0.9842 \\
Std Error & 0.0290 & 0.0177 \\
\hline
\end{tabular}

Note: Terms in brackets are t-statistics.

Table 5. Models of mean incomes of fulltime employees

\begin{tabular}{|c|c|c|}
\hline & Males & Females \\
\hline Constant & $\begin{array}{c}-0.990 \\
(-3.17)\end{array}$ & $\begin{array}{l}-0.445 \\
(-1.65)\end{array}$ \\
\hline ln $y_{i t-1}$ male & $\begin{array}{r}0.848 \\
(19.63)\end{array}$ & $\begin{array}{l}-0.052 \\
(1.39)\end{array}$ \\
\hline $\ln y_{i t-1}$ female & $\begin{array}{r}0.159 \\
(2.50)\end{array}$ & $\begin{array}{r}1.069 \\
(19.52)\end{array}$ \\
\hline $\begin{array}{l}\ln \mathrm{z}_{\mathrm{it}}(\mathrm{t}-1)-\ln \mathrm{z}_{\mathrm{it}-1}(\mathrm{t}-1) \\
\text { male }\end{array}$ & $\begin{array}{l}1.110 \\
(3.22\end{array}$ & $\begin{array}{r}0.230 \\
(0.77)\end{array}$ \\
\hline $\begin{array}{l}\ln \mathrm{z}_{\mathrm{it}}(\mathrm{t}-1)-\ln \mathrm{z}_{\mathrm{it}-1}(\mathrm{t}-1) \\
\text { female }\end{array}$ & $\begin{array}{r}0.645 \\
(1.72)\end{array}$ & $\begin{array}{c}1.526 \\
(4.704)\end{array}$ \\
\hline $\begin{array}{l}\ln z_{i t-1}(t-1)-\ln z_{i t-1}(t-1) \\
\text { male }\end{array}$ & $\begin{array}{r}5.100 \\
(5.06)\end{array}$ & $\begin{array}{r}2.415 \\
(2.78)\end{array}$ \\
\hline $\ln \mathrm{z}_{\mathrm{i} t-1}(\mathrm{t}-1)-\ln \mathrm{z}_{\mathrm{it}-1}(\mathrm{t}-1)$ & $\begin{array}{l}-1.364 \\
(-2.09)\end{array}$ & $\begin{array}{l}-0.183 \\
(-0.33)\end{array}$ \\
\hline $\ln p_{t}-\ln p_{t-1}$ male & $\begin{array}{r}0.313 \\
(2.93)\end{array}$ & $\begin{array}{r}0.371 \\
(4.04)\end{array}$ \\
\hline In $p_{t}-\ln p_{t-1}$ female & $\begin{array}{l}-0.066 \\
(-0.57)\end{array}$ & $\begin{array}{l}-0.178 \\
(1.78)\end{array}$ \\
\hline $\mathrm{R} 2$ & 0.9819 & 0.9765 \\
\hline Std Error & 0.0235 & 0.0203 \\
\hline
\end{tabular}

would be consistent with downward pressure on incomes, in areas with low participation rates or high unemployment.

An improved test of the model that local labour market conditions impact on incomes can be obtained by considering solely the incomes of those in fulltime employment. For this sub group the numbers in each occupational group are known at both censuses, and the national pattern of the occupational income distribution is also available. Using the national pattern it is therefore possible to construct values of $z_{i t-1}(t-1)$ and $z_{i t}(t-1)$ but also to construct $z_{i t-1}(t)$. Let $\mathrm{m}_{1 \mathrm{t}}=\left(\ln \mathrm{zit}_{\mathrm{t}}(\mathrm{t}-1)-\ln \mathrm{z}_{\mathrm{it}-1}(\mathrm{t}-1)\right)$ and $\mathrm{m}_{2 \mathrm{t}}=\left(\ln \mathrm{z}_{\mathrm{it}-1}(\mathrm{t})-\ln \mathrm{z}_{\mathrm{i}}\right.$ $\left.{ }_{t .1}(t-1)\right)$. Then $m_{1}$ is a measure of the change due to changes in occupational structure, and $\mathrm{m}_{2}$ is a measure of the change due to national changes in mean income within the occupational groups. These measures are calculated separately for both sexes. Instead of restricting the model to data on a single sex, in Table 5 we list the results of fitting the model including terms for both sexes for each variable. For both sexes, the variable values for the other sex carry some information which improves the fit.

There is considerable collinearity between the variables. Note that the sum of the coefficients on the previous income levels is close to one for both males and females. Thus incomes of both males and females at the previous time convey information about levels. However using just the income level for the same sex means little loss in both cases. For both sexes, the occupational change within the own sex group is highly significant and the estimates are not significantly different from one. Hence at the regional level, changes due to numbers in the occupational groups were approximated by the changes in proportions by occupation with national occupational income means applied to them. The most striking coefficients in these regressions are the terms associated with income changes at the occupational level. For both sexes the coefficients on changes in occupational incomes for males are much larger than one, and for males the coefficient is significantly larger than one.

The final pair of coefficients, those on changes in the participation rate, are positive for males and negative for females in both regressions. The mean of both participation rates is shown in Table 6. It is striking that changes of this magnitude appear to have had been associated with such limited changes in incomes.

Areas where the male employment participation was high relative to the mean, appeared to have a positive effect on mean incomes for both sexes. Since the participation rate fell in all areas, this means that there has been more downward pressure on incomes the larger the participation rate fall. However the effect is not large. If the regression for males is fitted without the insignificant female term, the coefficient falls to 0.26 . As a supply function, this would estimate the wage elasticity of employment as near 4 , which is excessively large. Again, the picture is one which is broadly consistent with a rationing model. For females the own participation rate is not significant in a two tailed test at the 5 percent level, but females seem to be able to extract some increase in incomes where the male participation rate 


\section{Table 6. Ratios of participations rates by electorate, 1991 to 1986, male and female}

\begin{tabular}{lll}
\hline & Males & Females \\
\hline Maximum & 0.958 & 1.058 \\
Q3 & 0.895 & 0.971 \\
Median & 0.866 & 0.943 \\
Q1 & 0.835 & 0.913 \\
Minimum & 0.713 & 0.783 \\
Mean & 0.861 & 0.939 \\
SD & 0.0454 & 0.0476
\end{tabular}

Note: Participation rate for each sex is defined as persons gainfully employed divided by total population within sex groups.

is higher. However there could be a large number of alternative reasons for this association. Again the data is consistent with a very elastic supply function for female labour, and with the rationing model as a good approximation.

\section{Some social effects in the regional patterns}

Many persons work in electorates different from the electorate in which they live. This is especially true in major urban areas. The persons employed at workplaces in an electorate may be quite different from those residing in the electorate. The data gives the numbers employed by residential location, not by employment location. In practise we have two distinct geographic patterns, with the set of accessible employment opportunities one of the criteria determining residential location. While our data show how persons in each residential area (the electorates) interact with the labour market, each electorate is not an independent labour market. Persons in some electorates may be employed in many others especially in the Auckland urban area.

Some part of the patterns which we observe may be associated with the factors influencing residential choice, rather than those determining labour market outcomes. To examine this we consider the deviations of the 1991 electorate occupation group mean incomes from the national averages. The data are the mean incomes by occupation group and sex, for all fulltime employees. For each electorate there are 16 observations generated by the 8 occupation and 2 sex groups. One of the occupation groups is those not adequately defined, and it generally has small numbers and poorly estimated mean incomes as a result.

The principal components of the observations give an indication of the main patterns in these deviations from national means. 74 percent of the generalised variance is captured by the first principal component. This component has positive coefficients on all 16 deviations, and indicates that the dominant pattern is for mean incomes in the different occupations to be correlated for dwelling location based groupings. The second component has 6 per cent of the variance and is associated with a different pattern for mean incomes of persons in Agriculture and the extractive industries. The next two components have large weights on the Not Adequately Defined group, and their importance is almost certainly overstated because of low numbers in these groups.

In the models reported earlier the term $\ln \mathrm{y}_{\mathrm{i} t-1}$ carries the main component of this association, and essentially acts as an error component for each electorate which is associated with the deviation from the pattern of incomes associated with $z_{i t-1}(t-1)$. By fitting a separate coefficient for this term, we add a great deal of adjustment to the specific local circumstances with a single model parameter.

The social effects introduced here are the sort of thing which would be expected with the model developed by Coleman(1996). In his model, allocative choices by individuals will mean that residential location is conditioned on income as well as occupation, and that different residential locations will have different interfaces to the labour market.

\section{Conclusions}

The available data structures constrain the analyses of the income patterns in both the whole population and those classed as gainfully employed. This paper has extended the analysis of Jackson(1995), and shown that occupation structure is a central feature of the income determination process. Using electorates as defined for the 1987 election as area units, it is shown that the occupation and workforce structure permit remarkably accurate pictures of the regional pattern of mean incomes. Moreover, changes in the occupational structure of the work force, and changes to occupational incomes at the national level, are sufficient to describe a high proportion of the variance of the change in mean incomes over time.

One of the key arguments for the Employment Contracts Act was that wages were locked into national patterns. The data of this paper shows that changes in national mean incomes in occupation groups provide a very good predictor of changes in incomes in all electorates. They therefore suggest national patterns were important in determining local changes in income levels irrespective of local labour market conditions. If that is felt to be significant evidence of an ineffective labour market, then it provides support for the existence of one effect the ECA tries to ameliorate. However our allowance for occupation differences raises many significant issues, and in particular the direction of causality in the income determination process. Were differences in the electorate occupation patterns possibly a source of some differential pressures on incomes. It would now be most interesting to examine if the patterns of 1986 to 1991 have been significantly altered over the past five years under the Act.

The importance of occupation in generating the income structure in regions naturally leads to questions of the level of detail in occupations required to construct policy models of the labour market. The present broad classification may be adequate, but it is likely that some further detail perhaps attempting to separate key construction industry occupa- 
tions would be worth while. This issue needs to be examined.

While there are significant associations between labour force participation and the residuals in the above relationships, they appear to contribute a very small part of the variance of changes in regional incomes.

\section{Future research}

Regional detail of incomes by occupation was only available for the 1991 Census. If it was also obtained for 1986 it would permit a much more detailed analysis of the interaction of local and national factors in labour market change. It would for example make it possible to ask if patterns of changed occupational structure in a local labour market were associated with changes in the average incomes of the corresponding occupational group. In recent policy debate, wage increases in a regional group, construction workers in Auckland, have often been quoted as a serious source of potential problems. It would obviously be useful to explore the general pattern of relationships between regional incomes by occupation, and resulting national averages.

The period 1986-1991 was one which closed with the introduction of the Employment Contracts Act. The more recent period 1991-1996 is the first five years under that Act. In view of the widespread interest in the effects of the ECA it would be very valuable to examine the more recent period, and see to what extent patterns observable in the period 1986-1991 are also found in this period. The period 19911996 largely spans years of upswing in the business cycle, and corresponding growth. Before making broader inferences from the rationing model which has been shown in an informal way to fit the data well, it is important to see if similar patterns are observed in the upswing. The tables for 1991 were designed to make it easy to match them with data from 1986 and 1996, so further work on these themes is facilitated.

\section{References}

Coleman, A. (1997) Urban joblessness, location and hysteresis-a theoretical approach. In Morrison, P.S. (ed.) Labour, employment and work in New Zealand 1997. Proceedings from the seventh conference, Victoria Unviersity of Wellington: 61-66

Jackson, L.F. (1995) A rationing model and regional labour markets. In Morrison, P.S. (ed.) Labour, employment and work in New Zealand 1994. Proceedings from the sixth conference, Victoria Unviersity of Wellington: 240--248

Malinvaud, E. (1977) The Theory of Unemployment Reconsidered. .Blackwell. Oxford.

\section{Acknowledgement}

The tabulations used in this paper were finances by research grants from the Internal Grants Committee of Victoria University of Wellington.

\section{Author}

Fraser Jackson is Emeritus Professor of Econometrics, Victoria University of Wellington, PO Box 600, Wellington. Email: fraser.jackson@vuw.ac.nz 